\title{
Estrogen suppresses hepatocellular carcinoma cells through ER $\beta$-mediated upregulation of the NLRP3 inflammasome
}

\author{
Qing Wei ${ }^{1,2,6}$, Pengbo Guo ${ }^{1,6}$, Kun Mu³ , Ying Zhang ${ }^{1}$, Wei Zhao ${ }^{1}$, Wanwan Huai ${ }^{1}$, Yumin Qiu ${ }^{1}$, Tao Li ${ }^{4}$, Xiaomin Ma', \\ Yafei Liư ${ }^{5}$, Xiaoyan Chen ${ }^{1}$ and Lihui Han ${ }^{1}$
}

Hepatocellular carcinoma (HCC) is one of the most common malignancies worldwide. The incidence of HCC is strikingly higher in males than in females. The remarkable gender disparity suggests an important role for sex hormones in HCC pathogenesis. Recently, estrogen has emerged as a protective factor in the development and progression of HCC, but whether it prevents and attenuates HCC, and the mechanism of protection, have not been elucidated. The present study shows that expression of estrogen receptor (ER) $\beta$ was significantly downregulated in HCC tissue compared with normal liver tissue; moreover, its expression level showed a significant negative correlation with disease progression and a positive correlation with the expression level of NLRP3 inflammasome components. In a previous study, we showed that loss of NLRP3 inflammasome in HCC tissue contributed to tumor progression, whereas the mechanism of its deregulation was not elucidated. In this study, we investigated the potential link between NLRP3 inflammasome and estrogen. Our data reveal that treatment with $17 \beta$-estradiol (E2) significantly inhibited the malignant behavior of HCC cells through E2/ER $\beta /$ MAPK pathway-mediated upregulation of the NLRP3 inflammasome. This study shows a novel link between ER $\beta$ and the NLRP3 inflammasome in HCC progression, which provides a potentially valuable therapeutic strategy for treatment of HCC patients.

Laboratory Investigation (2015) 95, 804-816; doi:10.1038/labinvest.2015.63; published online 25 May 2015

Hepatocellular carcinoma (HCC) is the most common primary malignancy of the liver and the third-leading cause of cancer-related mortality in the world. ${ }^{1}$ It is well recognized that HCC is a male-dominant disease. Rates of liver cancer in males are typically 2 to 4 times higher than in females, and males usually have a poorer prognosis than females. ${ }^{2}$ The remarkable gender disparity observed in the incidence of HCC suggests that the sex steroid hormone estrogen may elicit a protective effect against this disease. ${ }^{3-5}$

The biological functions of $17 \beta$-estradiol (E2), a major form of estrogen, are mainly mediated by its two specific estrogen receptors, $\mathrm{ER} \alpha$ and $\mathrm{ER} \beta$. The role of $\mathrm{ER} \alpha$ in carcinogenesis has been widely investigated and elucidated, whereas ER $\beta$ was first identified in 1996 (ref. 6) and the function of ER $\beta$ in HCC is not known. Moreover, the precise role of estrogen and the expression status of $\mathrm{ER} \beta$ receptors in
HCC still remain poorly understood. Therefore, in this study, we investigated the effect of E2 and its downstream signaling in HCC development.

The NLRP3 inflammasome is an intracellular multiprotein complex involved in the innate immune response to pathogens and other hazards. Our previous work demonstrated that expression of NLRP3 inflammasome components was significantly downregulated in HCC tissue compared with that in the adjacent non-cancerous tissue, and that the deregulation of the NLRP3 inflammasome was involved in HCC progression. ${ }^{7}$ On the basis of the involvement of E2 in hepatocarcinogenesis ${ }^{5,8,9}$ and its newly defined role in regulation of some NLRP3 inflammasome components, ${ }^{10}$ we speculated that E2 might be responsible for the deregulation of NLRP3 inflammasome in HCC progression and thus contribute, to a certain degree, to the gender disparity in HCC.

${ }^{1}$ Department of Immunology, Shandong University School of Medicine, Jinan, China; ${ }^{2}$ Medical Laboratory Diagnosis Center, Jinan Central Hospital Affiliated to Shandong University, Jinan, China; ${ }^{3}$ Department of Pathology, Shandong University School of Medicine, Jinan, China; ${ }^{4}$ Department of Gastroenterology, Provincial Hospital Affiliated to Shandong University, Jinan, China and ${ }^{5}$ Cancer Research Center, Shandong University School of Medicine, Jinan, China

Correspondence: Dr L Han, MD, PhD, Department of Immunology, Shandong University School of Medicine, 44 West Wenhua Road, Jinan 250012, China. E-mail: hanlihui@sdu.edu.cn

${ }^{6}$ These authors contributed equally to this work.

Received 10 October 2014; revised 2 March 2015; accepted 23 March 2015 
In this study, we investigated the potential link between estrogen and the NLRP3 inflammasome. Our data show that expression of $\mathrm{ER} \beta$, one of the $\mathrm{E} 2$ receptors, was significantly downregulated in HCC tissue, and that its expression level positively correlated with the presence of NLRP3 inflammasomes in HCC patients. Moreover, E2 treatment significantly increased the expression and activation of NLRP3 inflammasomes in HCC cells, which further led to a reversal of malignant behavior of HCC cells. These data reveal a surprising regulatory role of $\mathrm{E} 2$ in the carcinogenesis and progression of HCC, which indicate that gender disparity in HCC patients is caused, at least to a certain degree, by E2 through $\mathrm{ER} \beta$.

\section{MATERIALS AND METHODS}

Patients, Specimens, and Tissue Microarray Construction

A total of 127 primary HCC samples and the paired adjacent non-cancer liver tissue were used for the tissue microarray (TMA) construction (Shanghai Biochip, Shanghai, China). There were 110 men $(86.6 \%)$ and 17 women $(13.4 \%)$ with a mean age of 54.0 years. Detailed clinicopathologic characteristics of these 127 HCC cases were shown in Table 1. To validate the results of immunohistochemistry (IHC) analysis of TMAs, real-time PCR analysis was conducted from the paired liver cancer tissue and non-cancerous liver tissue from another cohort of 24 HCC patients. Furthermore, western blot analysis was carried out from the third cohort of 64 HCC patients. All of the enrolled patients were those underwent curative resection in the Department of Hepatobiliary Surgery of the Provincial Hospital Affiliated to Shandong University from February 2012 to July 2014. No patients received chemotherapy or radiotherapy before surgical resection. Cell differentiation based on tumor grading was determined using the Edmondson grading system, and clinical stages were classified according to the International Union against Cancer TNM classification system. Written ethical approvals were obtained from all of these patients before the initiation of this study. All of the protocols dealing with the patients were conformed to the ethical guidelines of the Helsinki Declaration and approved by Shandong University Research Ethics Committee.

\section{Immunohistochemical Staining and Scoring}

IHC was performed as previously described. ${ }^{7}$ The primary antibodies included rabbit monoclonal anti-human ASC (\#ADI-905-173, Enzo Life Sciences, San Diego, CA), IL-1 $\beta$ (\#ab2105, Abcam, Cambridge, MA), caspase 1 (\#AP6703c Abgent, Shanghai, China), ER $\beta$ (\#bs-0116R, Biosynthesis Biotechnology, Beijing, China), and mouse monoclonal antihuman NLRP3 (\#ab17267, Abcam). TMA slides were incubated with primary antibodies at $4{ }^{\circ} \mathrm{C}$ overnight, and then washed with PBS for three times. The slides were then incubated with biotinylated secondary antibody for $1 \mathrm{~h}$. Reaction products were visualized by incubating slides with 3,3'-diaminobenzidine, followed by counterstained with
Table 1 Clinicopathologic characteristics of 127 patients with HCC

Characteristics

No. of patients (\%)

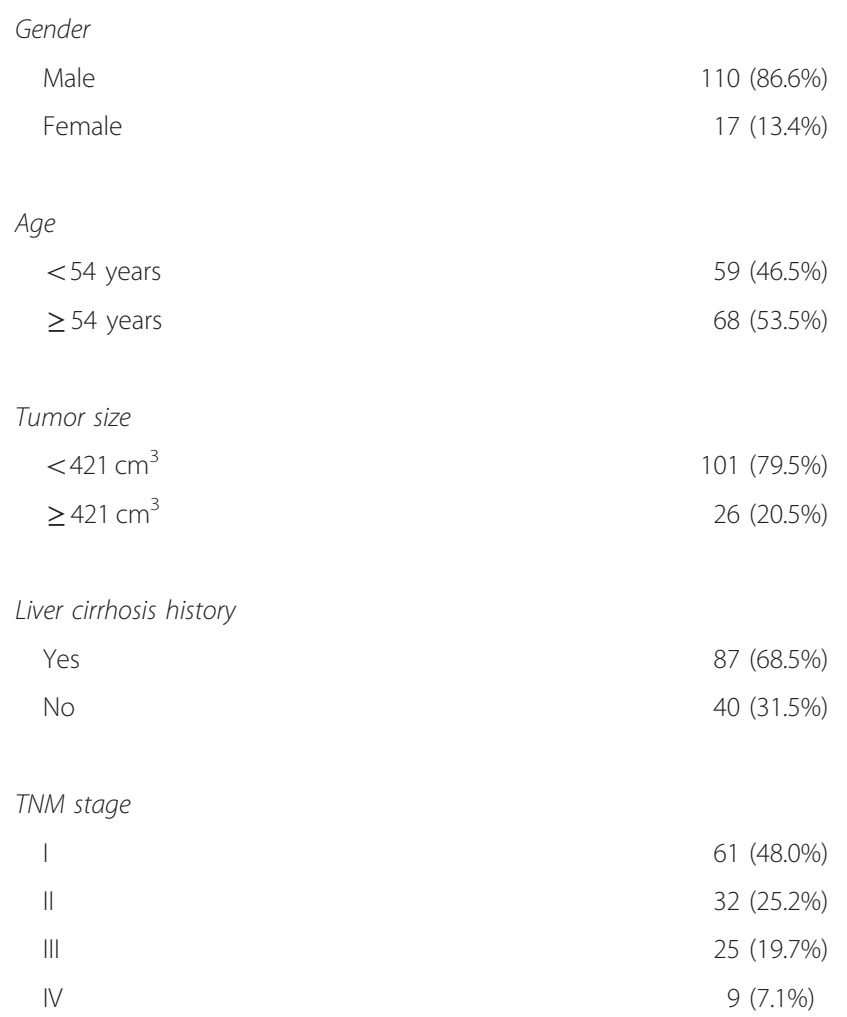

Edmondson grade

II

$18(14.2 \%)$

$90(70.8 \%)$

II

$19(15 \%)$

Regional lymph nodes

NO

$125(97.7 \%)$

N1

$2(2.3 \%)$

Distant metastasis

MO

$123(98.4 \%)$

M1

$4(1.6 \%)$

hematoxylin, dehydrated in alcohol and xylene, mounted in neutral gum, and analyzed using a bright field microscope.

The analysis of TMA slides was performed by two pathologists who were blinded to the clinical data, and the IHC staining degree was represented by the staining intensity. The intensity score was then classified into 4 scales, with $0=$ negative, $1=$ weak, $2=$ moderate, and $3=$ strong. Grade 0 and 1 were classified as low expression and grade 2 and 3 were considered as high expression. In parallel, immunohistochemical 
staining was also evaluated using Image-Pro Plus v6.2 software (Media Cybernetics, Bethesda, MD, USA) as previously described, ${ }^{7}$ and the relative expression level of each protein was quantified as integrated optical density.

\section{Cell Culture and E2 Treatment}

Human HCC cell lines, including BEL7402, SMMC7721, and HepG2 cells were obtained from Cell bank of Chinese Academy of Science (Shanghai, China) and were routinely cultured as described before. ${ }^{11,12}$ HCC cells were seeded in 24-well plates and incubated for $20 \mathrm{~h}$ before treatment with 10,50 , and $100 \mathrm{nM}$ of recombinant human $17 \beta$-estradiol (E2) (Sigma, St Louis, MO, USA) for another $24 \mathrm{~h}$ before being harvested for real-time PCR and western blot analysis.

\section{RT-PCR and Quantitative Real-Time PCR (qRT-PCR)}

Total RNA was extracted from HCC cells or fresh liver tissue of 24 HCC patients using TriZOL reagent (Invitrogen, Carlsbad, CA, USA) according to the manufacturer's directions. A total of $2 \mu \mathrm{g}$ of RNA was used for cDNA synthesis with a Reverse Transcription Kit (Toyobo, Osaka, Japan) in the $20 \mu \mathrm{l}$ reaction volume. Equal amounts of cDNA were subjected to PCR with the condition including an initial denaturation at $94{ }^{\circ} \mathrm{C}$ for $5 \mathrm{~min}$, followed by 40 cycles of $94{ }^{\circ} \mathrm{C}$ for $30 \mathrm{~s}, 54^{\circ} \mathrm{C}$ for $30 \mathrm{~s}, 72^{\circ} \mathrm{C}$ for $30 \mathrm{~s}$, and a terminal extension at $72{ }^{\circ} \mathrm{C}$ for $5 \mathrm{~min}$. After the reaction, $10 \mu \mathrm{l}$ of the PCR products were used for running in agarose gels, stained with ethidium bromide, and visualized using UV transillumination.

qRT-PCR was carried out using a Light Cycler (Bio-Rad, CFX96, USA) according to the manufacturer's instructions. Each sample was examined in triplicate and $\beta$-actin was used as the internal control. The primers we used for real-time PCR is listed in the online Supplementary Data. GraphPad Prism v5 (GraphPad Software, San Diego, CA, USA) was used to create the scatter plots. Data shown are representative figure from at least three independent experiments.

\section{Western Blot Analysis}

Total protein extractions were obtained from HCC cells or fresh liver tissue, and lysed in RIPA buffer before separated by SDS-polyacrylamide gel electrophoresis. The cell culture supernatant was collected and concentrated using the Amicon Ultra $10 \mathrm{~K}$ Centrifugal Filter Devices (Millipore, Billerica, MA, USA) before western blot assay. The primary antibodies included antibody against ER $\beta$ (\#ab3576) from Abcam company; antibodies against NLRP3 (\#ALX-804-818-C100) and ASC (\#ADI-905-173) from Enzo Life Sciences; antibodies against caspase 1 (\#S3866) and IL-1 $\beta$ (\#S2022) from Cell Signaling Technology (Danvers, MA, USA). $\beta$-Actin protein was detected as an internal control using the mouse anti- $\beta$ actin monoclonal antibody (\#ab6276, Abcam).

\section{Inflammasome Reconstitution}

NLRP3 inflammasome reconstitution was performed by transfecting the cells with eukaryotic expression plasmids, including $15 \mathrm{ng}$ of pcDNA3-myc-NLRP3, $5 \mathrm{ng}$ of pcDNA3myc-ASC, $5 \mathrm{ng}$ of pcDNA3-myc-procaspase1, and $150 \mathrm{ng}$ of pRC/cMV-proIL-1 $\beta$, using Lipofectamin 2000 from Invitrogen (Grand Island, NY, USA). The inflammasome components expression plasmids were kind gifts from Dr John C. Reed and the construction of these plasmids were described in the references. ${ }^{13,14}$ HCC cells were seeded in 24-well plates and incubated for $24 \mathrm{~h}$ before transient transfection with plasmids encoding NLRP3 inflammasome. Cells transfected with empty pcDNA3 plasmid were used as a mock control. Successful inflammasome reconstitution was confirmed by mRNA and protein assay of NLRP3 inflammasome components by RT-PCR and western blot, respectively. Caspase 1 activation was analyzed using a Caspase-1 Colorimetric Assay Kit (BioVision, CA, USA) according to its protocol. Secretion of IL- $1 \beta$ in the supernatant from inflammasome reconstituted cells was detected using ELISA kits (Dakewe Biotech Company, Shenzhen, China) according to the manufacturer's instruction.

\section{Cell Viability, Cell Death, and Colony Formation Assay}

Cell viabilities were analyzed using a CCK-8 kit (Dojindo Laboratories, Kumamoto, Japan) according to the manufacture's instruction. Cell death was detected by trypan blue staining and LDH release assay kit (Beyotime Biotechology, Beijing, China) according to the manuscripture's instruction. For the colony formation assay, HCC cells were seeded in sixwell plate at a density of $1 \times 10^{3}$ cells per well. After 7 days of incubation, survival colonies ( $>50$ cells per colony) were stained with $0.5 \%$ of crystal violet and counted under the microscope. The experiments were carried out in triplicate and repeated for at least three times.

\section{Cell Migration Assay}

Cell migration capability was studied by transwell migratory assay and wound healing assay. The transwell migratory assay was carried out using the transwell migratory apparatus (Costar, 6.5-mm diameter, $8-\mu \mathrm{m}$ pore size) as described before. ${ }^{5}$ For the wound healing assay, HCC cells were plated in the 24-well plate and incubated for $24 \mathrm{~h}$. Cell monolayers were then carefully wounded using a sterile $200-\mu$ l pipette tip to generate a cut of $\sim 1 \mathrm{~mm}$ in width. After washing twice with PBS, cells were incubated in RPMI 1640 growth medium containing 3\% FBS for $24 \mathrm{~h}$. Distance of cell migration was determined by measuring width of the wound and calculated using the width difference from treated HCC cells divided by that from mock control cells.

\section{Statistical Analysis}

Data were analyzed using SPSS 16.0 (SPSS, IL, USA) and a $P$-value of $<0.05$ was considered statistically significant. $\chi^{2}$-tests and $t$-test were applied to compare categorical 

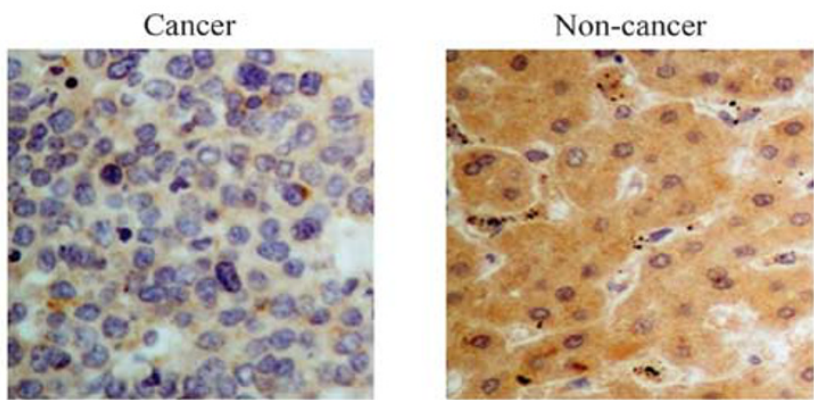

C
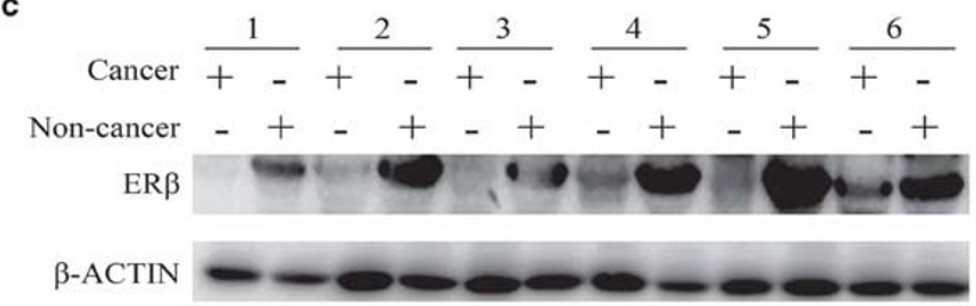

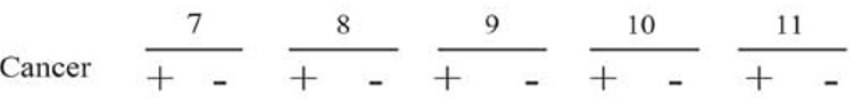

Non-cancer
ER $\beta$

\section{$\beta$-ACTIN}

e

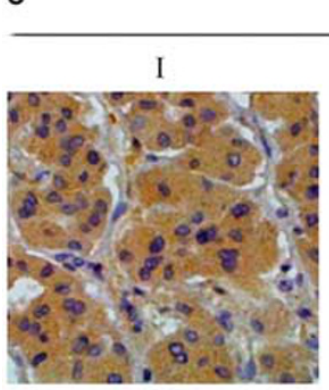

f

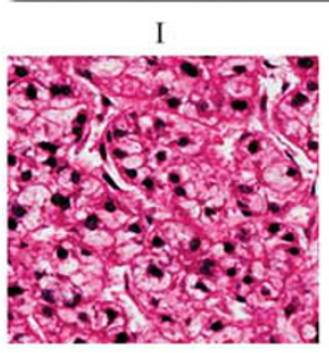

IHC
II

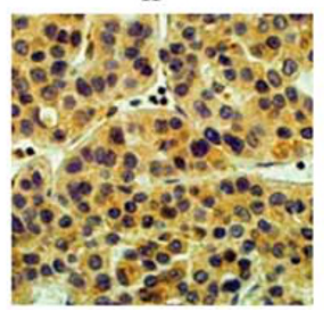

HE

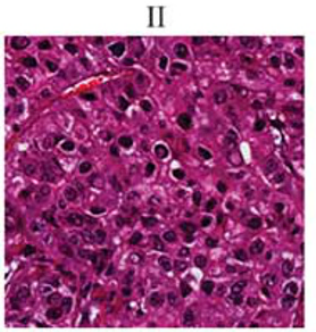

III

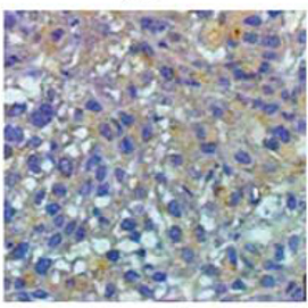

\section{III}

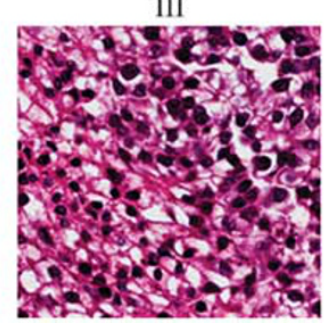

b

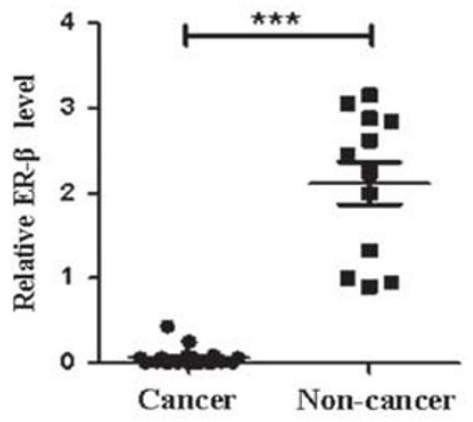

d

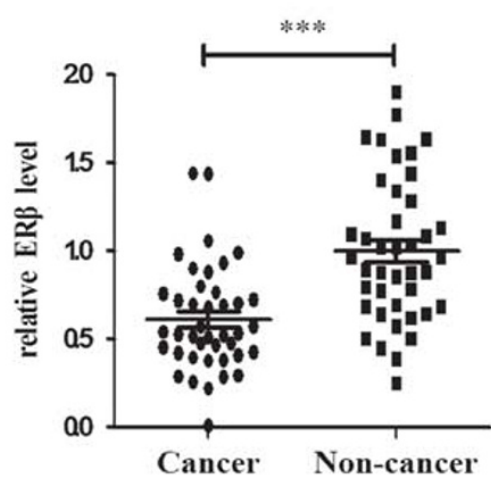

g

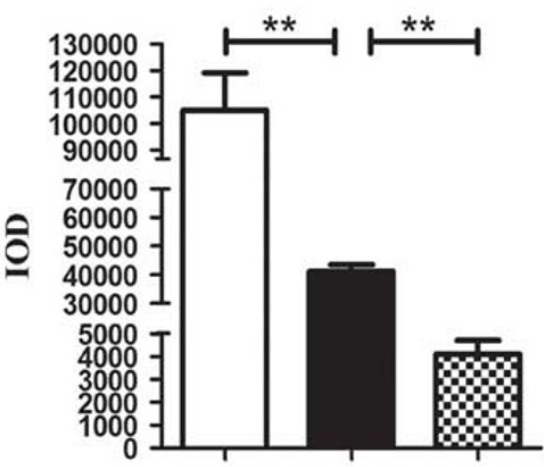

Grade I Grade II Grade III

Figure 1 ER $\beta$ deficiency in HCC tissue correlates with advanced HCC pathological grades and TNM stages. (a) Immunohistochemistry (IHC) staining of ER $\beta$ in hepatocellular carcinoma (HCC) tissue and corresponding non-cancerous liver tissue. (b) mRNA expression of ER $\beta$ was quantified by real-time PCR in HCC tissue and paired non-cancerous liver tissue from 24 HCC patients. (c) Western blot analysis of protein levels of ER $\beta$ from HCC tissue and paired non-cancerous liver tissue from another cohort of $64 \mathrm{HCC}$ patients. The pictured blots are representative data from $11 \mathrm{HCC}$ patients. (d) Statistical analysis of the western blot data from the HCC tissue and paired non-cancerous liver tissue. (e) Photograph of IHC for ER $\beta$ in Edmonson grade I, grade II, and grade III liver cancer tissue. (f) HE staining of the same cores to identify the Edmonson Grade of HCC tissue. (g) Quantitative analysis of ER $\beta$ expression in cancerous and non-cancerous liver tissue using Image-Pro Plus v6.2 software. ${ }^{* *} P<0.01$ and $\left.{ }^{* *} P<0.001\right)$. ER $\beta$, estrogen receptor $\beta$. 
variables and continuous variables, respectively. Spearman's rank correlation test was used to evaluate correlations between variables.

\section{RESULTS}

\section{ER $\beta$ Expression was Significantly Downregulated in HCC} Tissue

On the basis of our preliminary results showing deregulation of NLRP3 inflammasomes in HCC progression and the potential role of E2 in HCC development, we examined whether E2 was involved in HCC progression by its regulation of NLRP3 inflammasomes. To define the role of E2 in NLRP3 inflammasome deregulation in HCC, we determined the expression of $\mathrm{ER} \beta$ in HCC tissue and corresponding noncancerous liver tissue using IHC. Our IHC data show that $\mathrm{ER} \beta$ expression was significantly downregulated in HCC tissue compared with that in adjacent non-cancerous liver tissue (Figure 1a). A $\chi^{2}$-test analysis showed significantly decreased ER $\beta$ immunoreactivity in HCC tissue compared with that of the corresponding non-cancerous liver tissue (41.7 vs 93.7\%, $P<0.001$, Table 2). The decreased expression tendency of ER $\beta$ in HCC tissue was confirmed by real-time PCR $(P<0.001$, Figure 1b). Validation of the expression tendency of ER $\beta$ was further performed by western blot analysis in paired HCC tissue and non-cancerous liver tissue from another cohort of 64 HCC patients. Our western blot data also confirmed the decreased expression of ER $\beta$ in HCC tissue $(P<0.001$, Figure $1 \mathrm{c}$ and $\mathrm{d})$.

Table 2 ER $\beta$ expression was decreased in liver cancer tissues compared with non-cancerous liver tissues

\begin{tabular}{lcccc}
\hline & Cancer (\%) & Non-cancer (\%) & $x^{2}$ & P-value \\
\hline ERß & & & & \\
Negative & $58.3(74 / 127)$ & $6.3(8 / 127)$ & 62.132 & 0.000 \\
Positive & $41.7(53 / 127)$ & $93.7(119 / 127)$ & & \\
& & & & \\
\hline
\end{tabular}

\section{ER $\beta$ Deficiency Correlated with Advanced HCC Pathological Grades and TNM Stages}

We have shown that expression of ER $\beta$ was significantly decreased in HCC tissue; therefore, we wished to determine whether this downregulation correlated with disease progression. IHC staining data showed that HCC patients with more advanced pathological grades and clinical stages tended to exhibit lower ER $\beta$ immunoreactivity (Figure 1e and f). This decreased expression of $\mathrm{ER} \beta$ in advanced pathological grades of HCC tissue was further confirmed using Image Pro Plus v6.2 analysis $(P<0.01$, Figure 1g). Spearman correlation analysis was performed between ER $\beta$ expression and clinicopathological characteristics based on the IHC scores, which showed that ER $\beta$ protein levels significantly negatively correlated with the clinical stages and pathological grades of the HCC patients $(P<0.001$, Table 3$)$. These results indicate a potential involvement of $\mathrm{E} 2$ in the HCC progression via its $\mathrm{ER} \beta$ receptor.

\section{ER $\beta$ Expression Positively Correlated with NLRP3 Inflammasome Components}

Our previous study showed that expression of NLRP3 inflammasome components was significantly downregulated in HCC tissue and its expression level showed significant negative correlation with disease progression. ${ }^{7}$ On the basis of the same expression tendency of $\mathrm{ER} \beta$, we believed that $\mathrm{ER} \beta$ expression may also be correlated with the expression levels of NLRP3 inflammasome components. Statistical analysis of the IHC scores indeed defined positive correlations between the expression level of $\mathrm{ER} \beta$ and that of NLRP3 inflammasome components, including NLRP3, ASC, caspase 1 , and IL- $1 \beta(P<0.001$, Table 4$)$. In addition, real-time PCR data also revealed that expression level of $\operatorname{ER} \beta$ showed significant positive correlation with expression of NLRP3 inflammasome components $(P<0.05$, Figure 2$)$.

\section{The NLRP3 Inflammasome was Upregulated by E2 in the ER/MAPK/ERK Pathway}

In order to further define the regulatory role of E2 for NLRP3 inflammasome components, we treated the HCC cell with E2

Table 3 ER $\beta$ expression (IHC staining) was associated with clinical stage and pathological grade of HCC

\begin{tabular}{|c|c|c|c|c|c|c|c|c|c|c|c|c|c|}
\hline & Male & Female & $<54$ & $\geq 54$ & $<6.5$ & $\geq 6.5$ & 1 & $\|$ & III & 1 & II & III & IV \\
\hline \multicolumn{14}{|l|}{$E R \beta$} \\
\hline- & 60 & 14 & 35 & 39 & 46 & 28 & 6 & 56 & 12 & 25 & 21 & 19 & 9 \\
\hline \multirow[t]{3}{*}{+++} & 1 & 0 & 1 & 0 & 1 & 0 & 1 & 0 & 0 & 0 & 1 & 0 & 0 \\
\hline & \multicolumn{2}{|c|}{$r=-0.184$} & \multicolumn{2}{|c|}{$r=0.027$} & \multicolumn{2}{|c|}{$r=-0.114$} & \multicolumn{3}{|c|}{$r=-0.188$} & \multicolumn{4}{|c|}{$r=-0.345$} \\
\hline & \multicolumn{2}{|c|}{$P=0.038^{*}$} & \multicolumn{2}{|c|}{$P=0.760$} & \multicolumn{2}{|c|}{$P=0.201$} & \multicolumn{3}{|c|}{$P=0.034^{*}$} & & \multicolumn{3}{|c|}{$P=0.000^{* *}$} \\
\hline
\end{tabular}

${ }^{*} P<0.05$ and ${ }^{* *} P<0.001$ by statistical analysis using Spearman correlation test. 
and detected the expression of NLRP3 inflammasome components. In all of the following experiments, three HCC cell lines, BEL7402, SMMC7721, and HepG2 cells, were used and representative data are presented. The HCC cells were treated with E2 $(100 \mathrm{nM})$ for $24 \mathrm{~h}$, followed by expression analysis of NLRP3, ASC, caspase 1, and IL-1 $\beta$. Real-time PCR analysis showed that expression of NLRP3 inflammasome components were significantly increased in E2-treated cells (Figure $3 \mathrm{a}$ and $\mathrm{b}$ ), which was further confirmed at the protein level using western bloting (Figure 3c). Western blot data also showed that upregulation of NLRP3 inflammasome components was coordinated with MAPK/ERK pathway activation after E2 treatment (Figure 3c), which indicated that NLRP3 inflammasome was upregulated by E2 through ER $\beta / \mathrm{MAPK} /$

Table 4 ER $\beta$ expression (IHC staining) was positively correlated with NLRP3 inflammasome component expression

\begin{tabular}{|c|c|c|c|c|c|c|c|c|}
\hline \multirow[t]{2}{*}{$E R \beta$} & \multicolumn{2}{|c|}{$N L R P 3$} & \multicolumn{2}{|c|}{ ASC } & \multicolumn{2}{|c|}{ Caspase 1} & \multicolumn{2}{|c|}{$I L-1 \beta$} \\
\hline & Low & High & Low & High & Low & High & Low & High \\
\hline Low & 26 & 39 & 36 & 30 & 50 & 32 & 34 & 31 \\
\hline High & 18 & 141 & 31 & 124 & 20 & 154 & 18 & 133 \\
\hline $\mathrm{R}$ & \multicolumn{2}{|c|}{0.328} & \multicolumn{2}{|c|}{0.344} & \multicolumn{2}{|c|}{0.518} & \multicolumn{2}{|c|}{0.433} \\
\hline$P$ & \multicolumn{2}{|c|}{$0.000^{* *}$} & \multicolumn{2}{|c|}{$0.000^{* *}$} & \multicolumn{2}{|c|}{$0.000^{* *}$} & \multicolumn{2}{|c|}{$0.000^{* *}$} \\
\hline
\end{tabular}

**P $<0.001$ by statistical analysis using Spearman correlation test.
ERK pathway. To further verify this mechanism, we pretreated the HCC cells with ER $\beta$-specific inhibitor THTPP or MAPK pathway inhibitor PD98059 before E2 treatment, and detected the expression of NLRP3 inflammasome. Our data show that incubation of HCC cells with either THTPP or PD98059 could efficiently abrogate the increased expression of NLRP3 inflammasome components, which was both confirmed at protein level using western blot (Figure 3d and e) and at mRNA level using real-time PCR (Figure 3f). These results demonstrated that E2 stimulation induced significant upregulation of NLRP3 inflammasome compo-

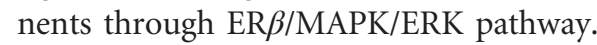

\section{Reconstitution of NLRP3 Inflammasome Reversed Malignant Behaviors of HCC Cells}

We have demonstrated that NLRP3 inflammasome expression was downregulated in HCC patients, and their decreased expression correlated with poorer cell differentiation and advanced clinical stages; ${ }^{7}$ then, we asked whether deregulation of NLRP3 inflammasome in HCC contributed to cancer progression. To answer this question and further define the role of NLRP3 inflammasome molecular platform in liver cancer, we reconstituted NLRP3 inflammasome in HCC cells and investigated the change of malignant behaviors of these cells.

HCC cells were transiently co-transfected with plasmids encoding NLRP3, ASC, pro-Caspase1, and pro-IL-1 $\beta$. Significantly increased expression of each component of NLRP3 inflammasome in the reconstituted HCC cells was confirmed
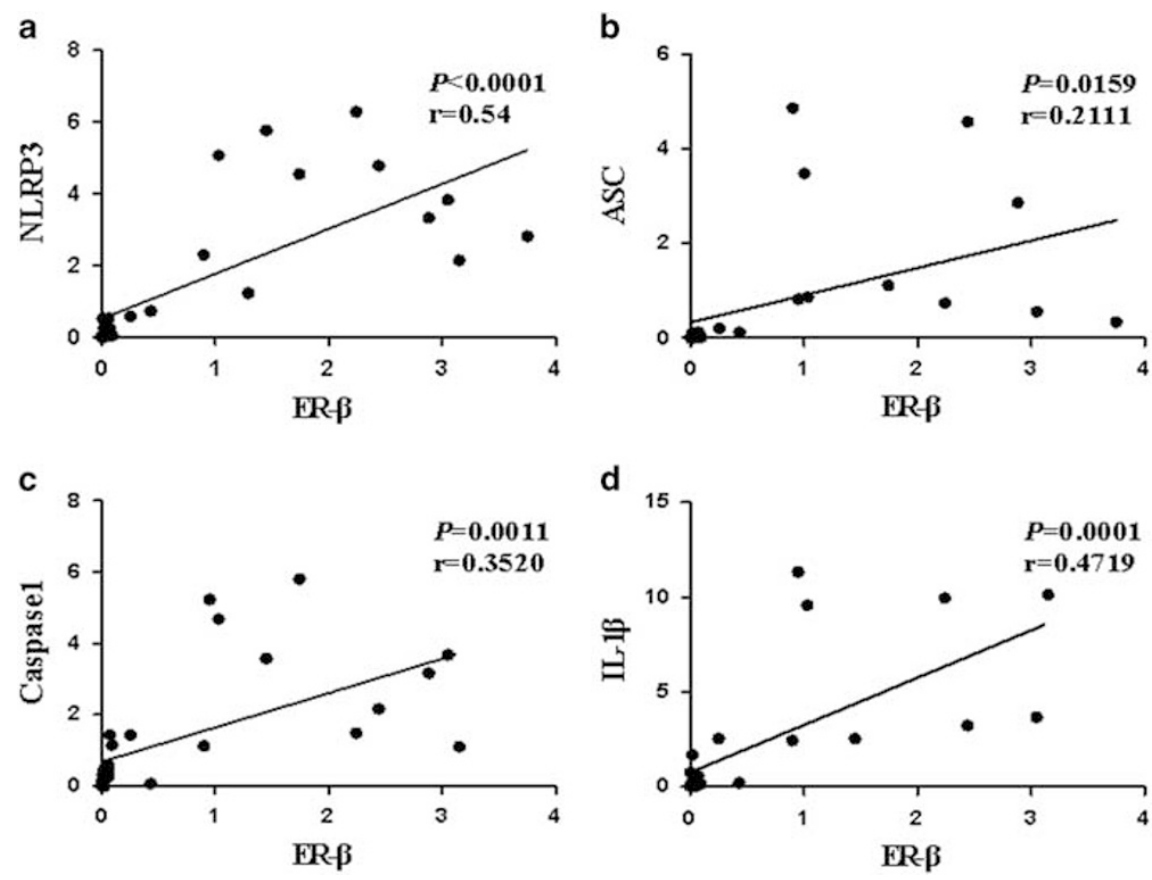

Figure 2 ER $\beta$ expression positively correlates with NLRP3 inflammasome components. (a-d) Real-time PCR was performed to detect the mRNA expression of NLRP3 inflammasome components and ER $\beta$ in liver cancer tissue and corresponding non-cancerous liver tissue from 24 HCC patients. The correlation analysis was performed to analyze the expression level between ER $\beta$ and NLRP3 (a), ASC (b), caspase 1 (c), and IL-1 $\beta$ (d) at mRNA level from HCC tissue and corresponding non-cancerous liver tissue. ER $\beta$, estrogen receptor $\beta$; HCC, hepatocellular carcinoma. 
a
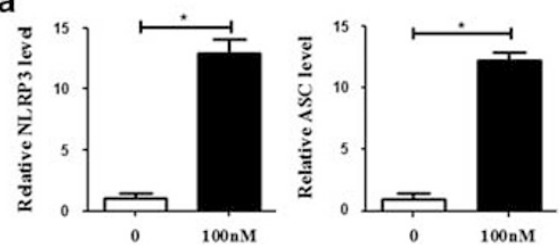

b
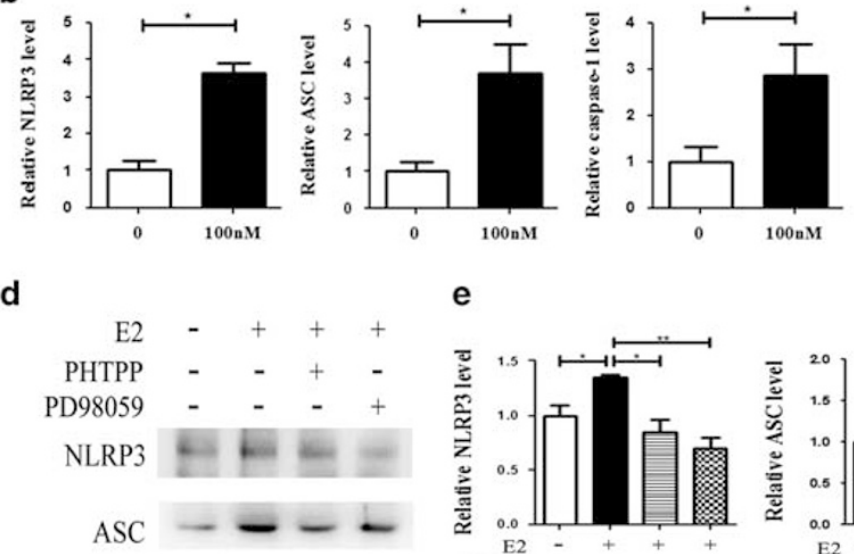

pro-caspasel

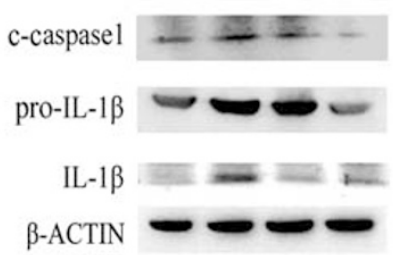

$\beta$-ACTIN e
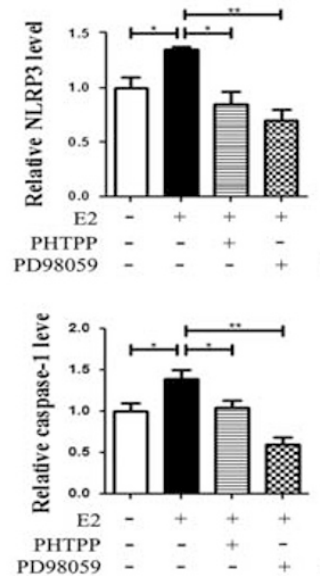
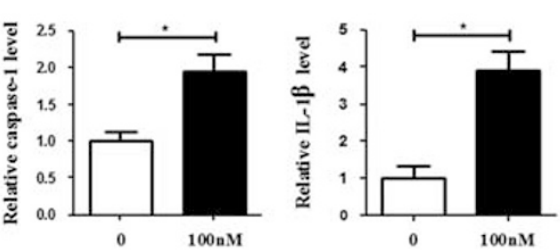

C

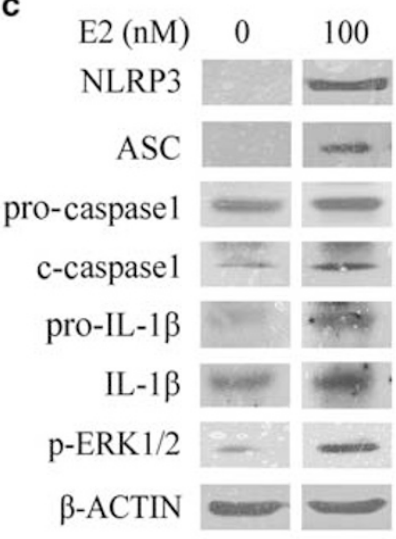

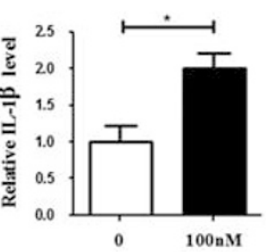

IL-1 $\beta$

$\beta$-ACTIN f
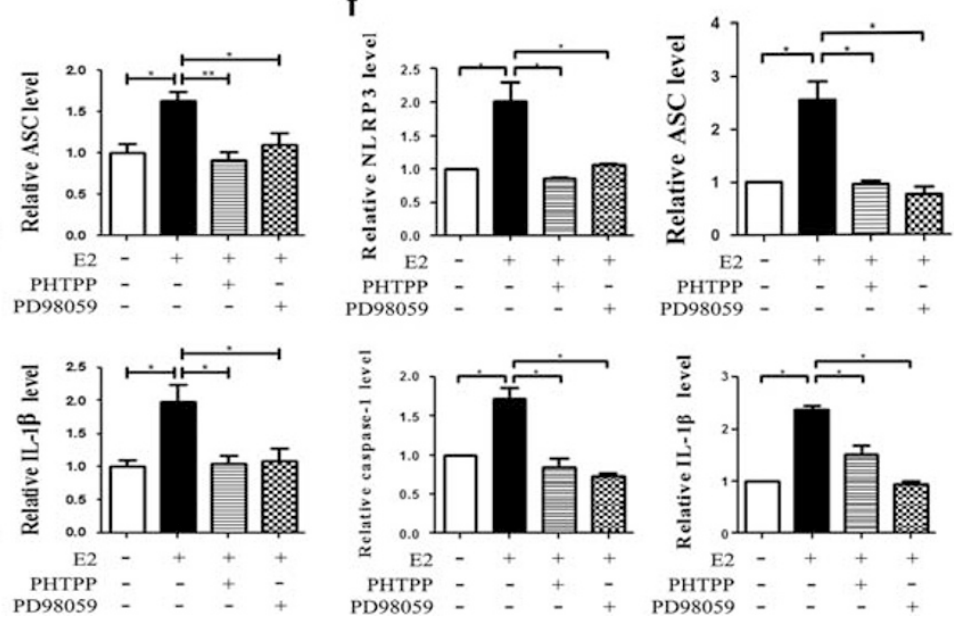

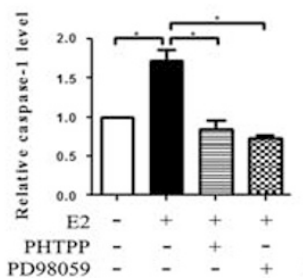

Figure 3 NLRP3 inflammasomes were upregulated by E2 in the ERß/MAPK/ERK pathway. (a and b) BEL7402 cells (a) and HepG2 cells (b) were treated with $100 \mathrm{nM}$ of E2 for $24 \mathrm{~h}$, and mRNA expression of NLRP3 inflammasome components were detected by real-time PCR. (c) Protein levels of NLRP3 inflammasome components in BEL7402 cells with E2 $(100 \mathrm{nM})$ treatment were detected by western blot. (d-f) The BEL7402 cells were pretreated with ER $\beta$ inhibitor PHTPP $(1 \mu \mathrm{M})$ or MAPK pathway inhibitor PD98059 $(20 \mu \mathrm{M})$ for $30 \mathrm{~min}$ before E2 $(100 \mathrm{nM})$ treatment for $24 \mathrm{~h}$. Protein and mRNA expression of NLRP3 inflammasome components were detected using western blot (d) and real-time PCR (f), respectively. Histogram (e) represented the corresponding quantitative analysis of the intensities of western blot bands. All of the experiments were repeated at least three times and representative data are shown. $\left({ }^{*} P<0.05\right.$ and $\left.{ }^{* *} P<0.01\right)$. HCC, hepatocellular carcinoma.

by RT-PCR (Figure 4a) and immunoblotting (Figure $4 \mathrm{~b}$ ). Caspase 1 undergoes autoproteolysis once the inflammasome is formed, further cleaves its downstream molecules, and releases the mature form of IL- $1 \beta,{ }^{15}$ so we detected both of the pro-form and cleaved form of caspase 1 and IL- $1 \beta$ in the inflammasome reconstituted cells. As shown in Figure 4b, the cleaved form of caspase 1 and IL-1 $\beta$ were significantly increased (in both the cell lysates and supernatants) in the NLRP3 inflammasome-reconstituted cells compared with mock control. These data indicated successful reconstitution of NLRP3 inflammasome in HCC cells.

Then, we detected a series of malignant behaviors of HCC cells in these inflammasome reconstituted cells. Cell viability was investigated by CCK- 8 assay and our data indicate that inflammasome reconstituted cells exhibited decreased cell viability, which revealed that reconstitution of NLRP3 inflammasome significantly inhibited proliferation of these HCC cells (Figure $4 \mathrm{c}$ and d). Trypan blue staining and LDH release assay showed that NLRP3 inflammasome reconstitution significantly induced cell death of these HCC cells (Figure $4 \mathrm{e}, \mathrm{f}$ and $\mathrm{g}$ ). It is well recognized that NLRP3 inflammasome activation induced caspase 1-dependent cell death, named pyroptosis. ${ }^{16,17}$ Caspase 1 activation assay and IL-1 $\beta$ ELISA assay showed that significant caspase 1 activation (Figure $4 \mathrm{~h}$ and $\mathrm{i}$ ) and IL- $1 \beta$ secretion (Figure $4 \mathrm{j}$ and $\mathrm{k}$ ) were detected in the NLRP3 inflammasome reconstituted cells. These data indicate that NLRP3 inflammasome reconstitution induced caspase 1-dependent pyroptosis. To further verify the migratory capability of NLRP3 inflammasome in the malignant behaviors of these HCC cells, we performed transwell migratory assay and wound healing assay in these NLRP3 inflammasome reconstituted HCC cells. Transwell migratory assay showed that NLRP3 inflammasome reconstituteion significantly inhibited migratory capability of HCC cells $(P<0.01$, Figure 41$)$, which was further confirmed by wound healing assay $(P<0.05$, Figure $4 \mathrm{~m}$ and $\mathrm{n})$. Altogether, 
a

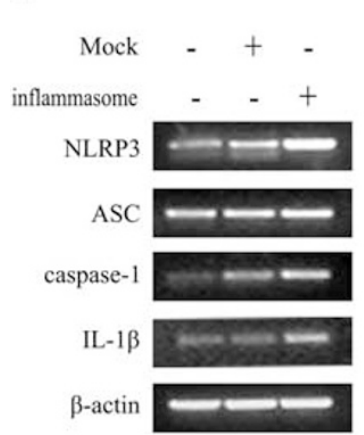

b

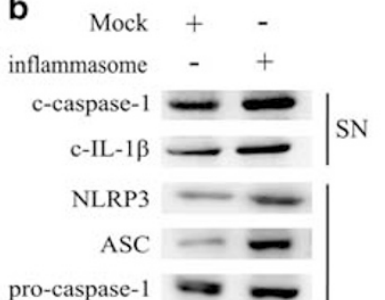

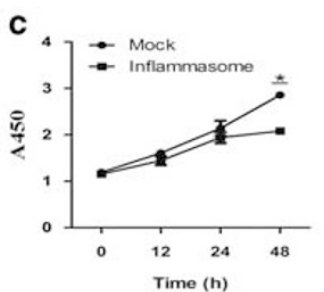

$\begin{array}{ccc}\text { pro-caspase-1 } & \longrightarrow \\ \text { c-caspase-1 } & -\infty\end{array}$

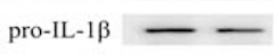

c-IL-1 $\beta$

$\beta$-ACTIN
CL d

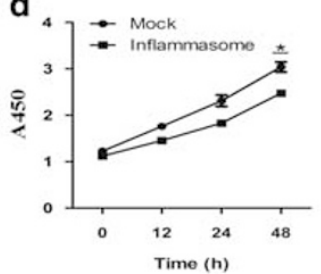

e

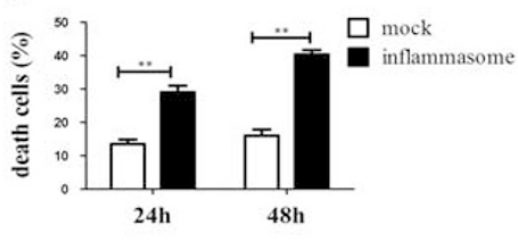

f

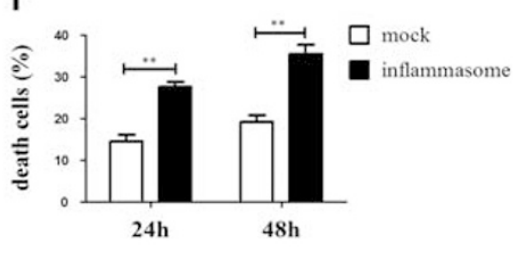

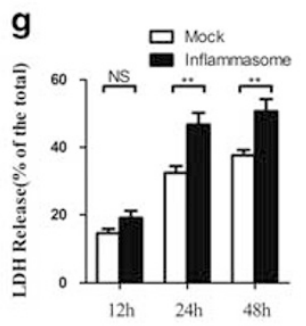
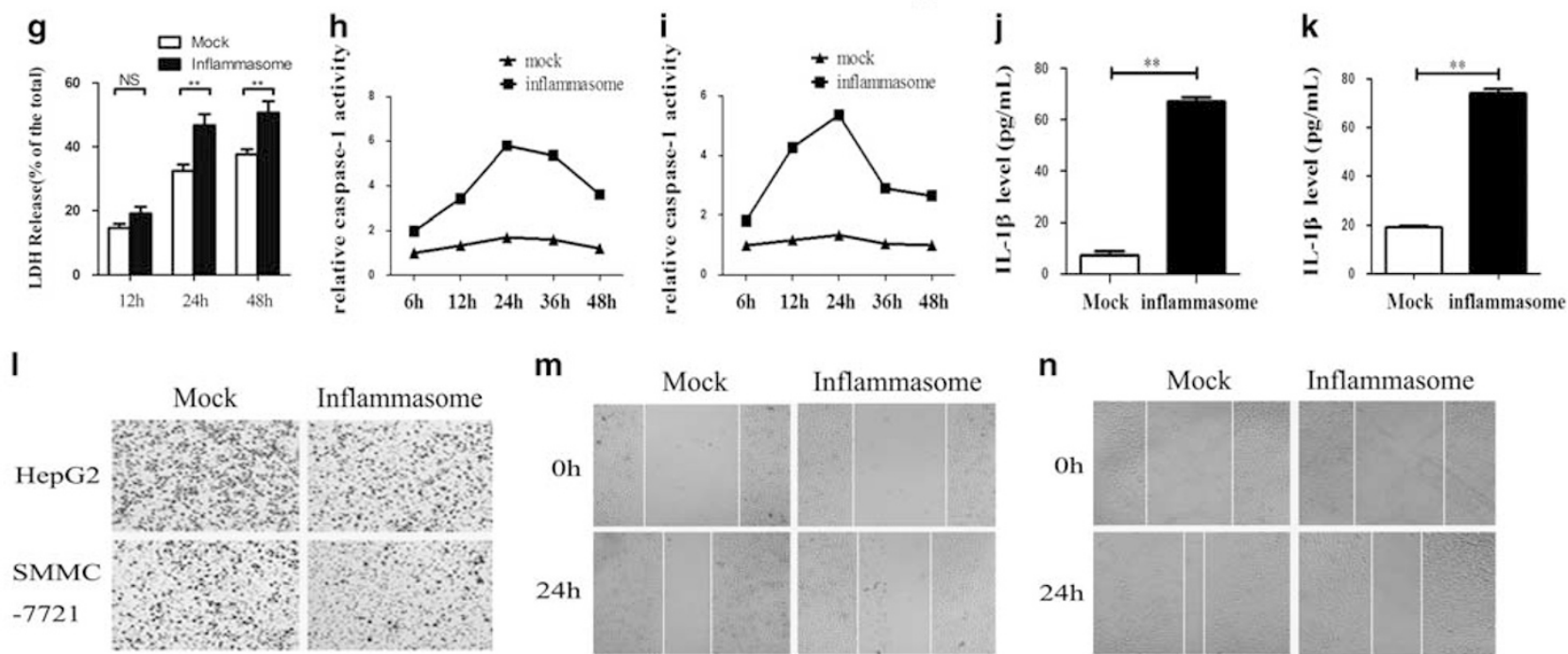

m
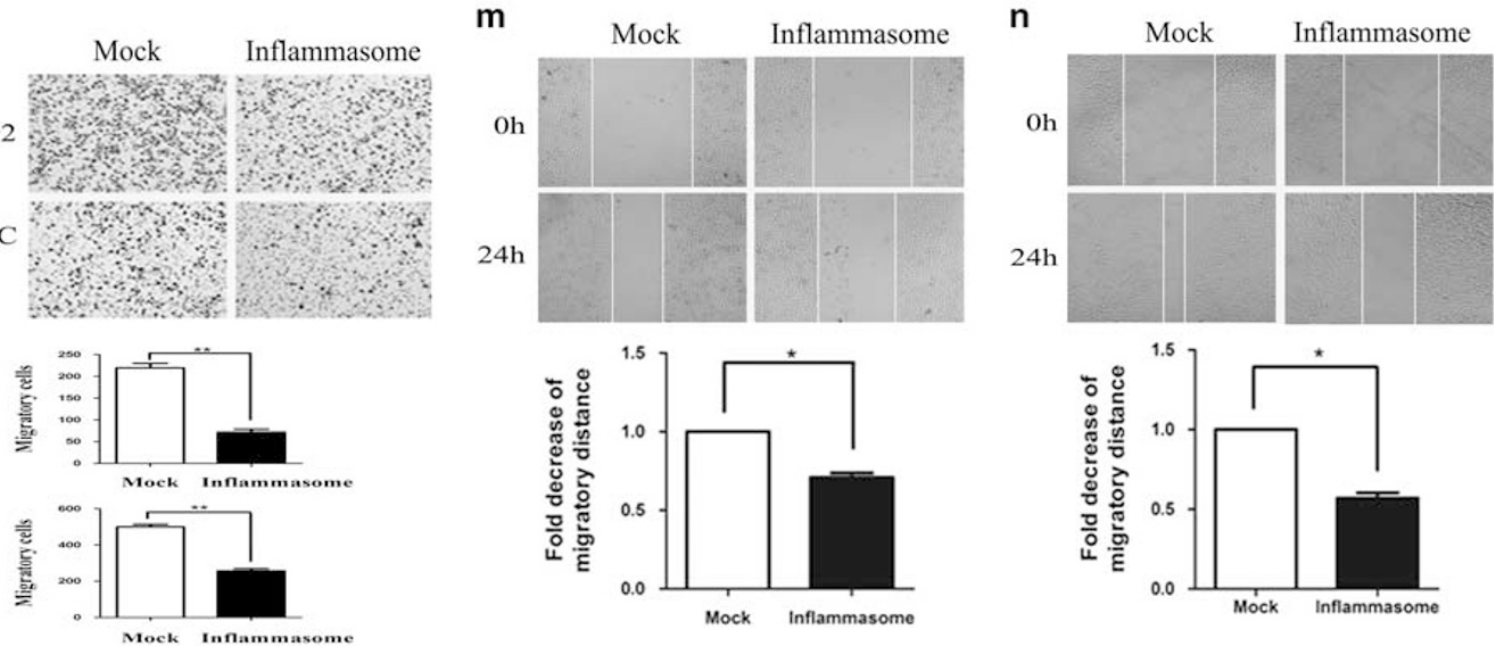

Figure 4 Reconstitution of NLRP3 inflammasomes and the functional verification of NLRP3 inflammasomes in HCC cells. (a and b) BEL7402 cells were transfected with $15 \mathrm{ng}$ of pcDNA3-myc-NLRP3, $5 \mathrm{ng}$ of pcDNA3-myc-ASC, $5 \mathrm{ng}$ of pcDNA3-myc-pro-caspase1, and $150 \mathrm{ng}$ of pRC/cMV-pro-IL- $1 \beta$ for NLRP3 inflammasome reconstitution. The cells transfected with empty pcDNA3 plasmid were used as mock controls. The mRNA and protein expression of NLRP3 inflammasome components in the transfected cells was determined by RT-PCR (a) and western blot (b), respectively. The cleaved form of caspase 1 and IL-1 $\beta$ in both the cell lysates (CLs) and the supernatants (SNs) were detected by western blot (b). (c and d) HepG2 cells (c) and BEL7402 cells (d) transfected with empty vector and plasmids encoding NLRP3 inflammasome components were cultured for $0,12,24$, and $48 \mathrm{~h}$ before cell viability assay using CCK-8 kit. (e and f) BEL7402 cells (e) and SMMC7721 cells (f) were transfected with empty vector and plasmids encoding NLRP3 inflammasome components. Cell death were analyzed by Trypan blue staining at 24 and $48 \mathrm{~h}$ after the transfection. (g) BEL7402 cells were transfected with plasmids encoding NLRP3 inflammasome components or vector control. LDH release assay was performed at 12, 24, and $48 \mathrm{~h}$ after the transfection to determine the cytotoxic effect of NLRP3 inflammasome reconstitution on HCC cells. (h and i) BEL7402 cells (h) and SMMC7721 cells (i) were transfected with empty vector or plasmids encoding NLRP3 inflammasome component, and cultured for up to $48 \mathrm{~h}$. The caspase 1 activation level in the mock and inflammasome reconstituted HCC cells were detected at $6,12,24,36$, and $48 \mathrm{~h}$ after the transfection. (j and $\mathbf{k}) \mathrm{IL}-1 \beta$ secretion from the inflammasome reconstituted BEL7402 cells (j) and SMMC7721 cells (k) were detected using IL-1 $\beta$ ELISA kit. (I-n) After reconstitution of the NLRP3 inflammasome in HCC cells, transwell invasion assay (I) and wound scratch assay ( $\mathbf{m}$ and $\mathbf{n}, \mathbf{m}$ for HepG2 cells and $\mathbf{n}$ for BEL7402 cells) were performed to investigate the migratory ability of HCC cells in which NLRP3 inflammasome was reconstituted. All the experiments were repeated at least three times and representative data are shown. $\left({ }^{*} P<0.05,{ }^{* *} P<0.01\right.$, and ${ }^{* * *} P<0.001$ for the inflammasome reconstituted cells compared with the mock control cells). HCC, hepatocellular carcinoma. 
a

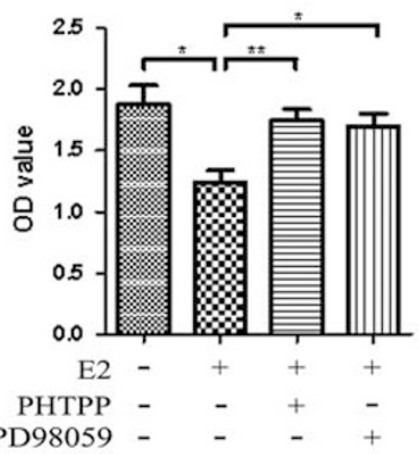

d
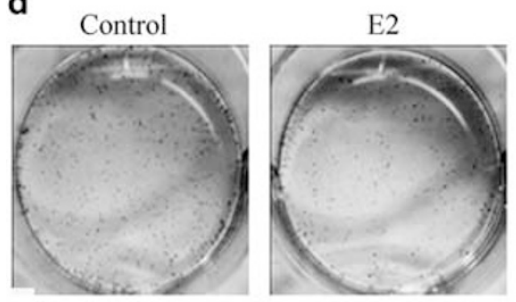

e
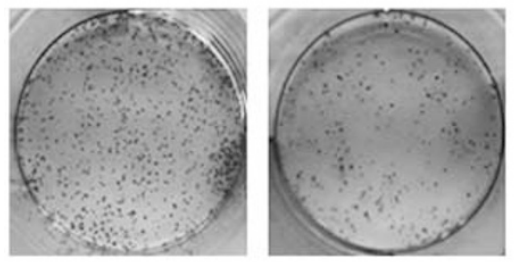

f Control E2
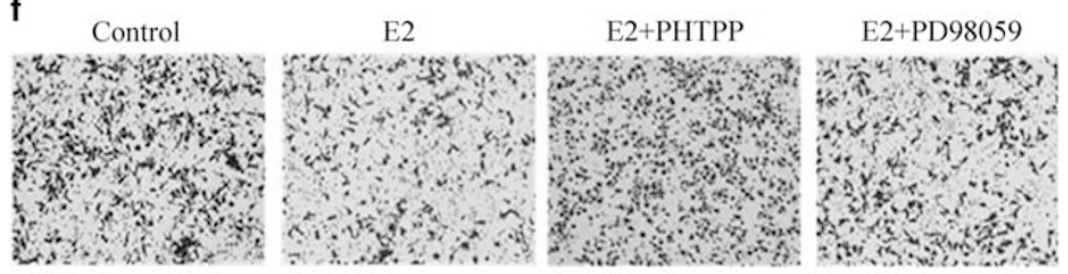

g

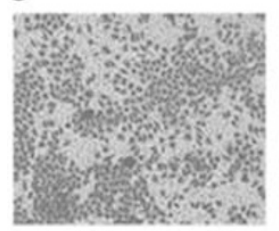

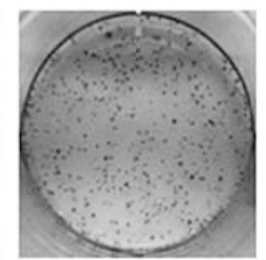

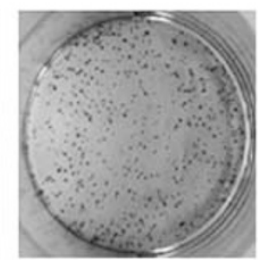

E2+PHTPP

b
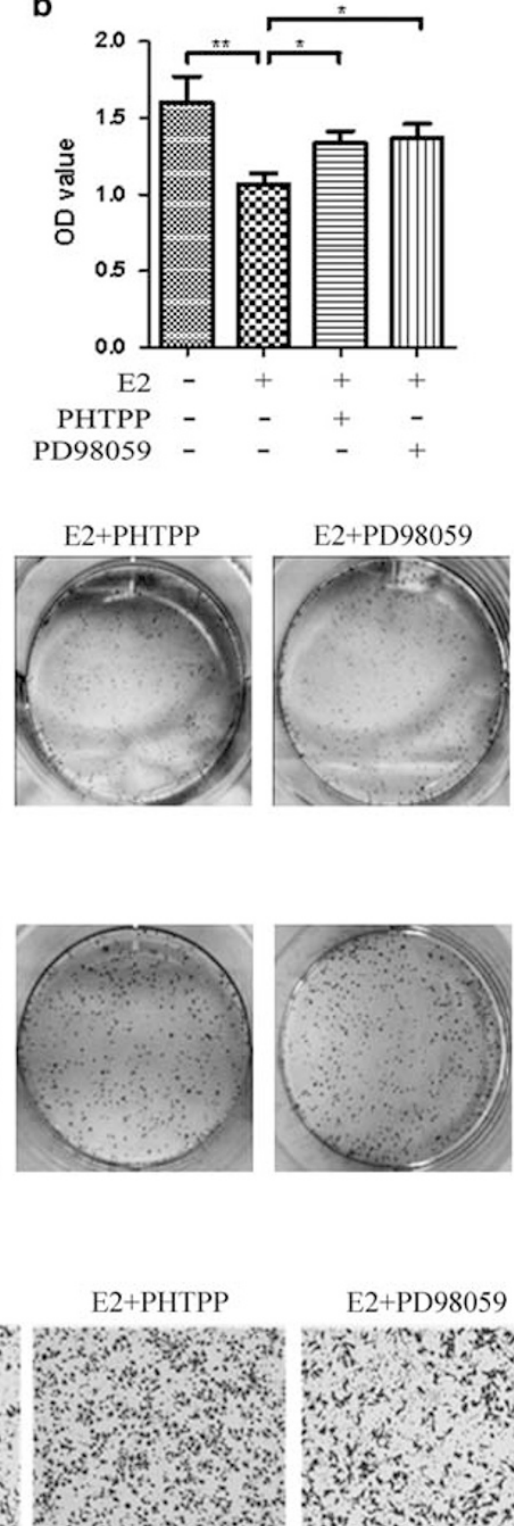

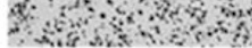

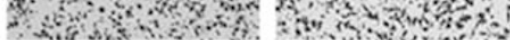

c
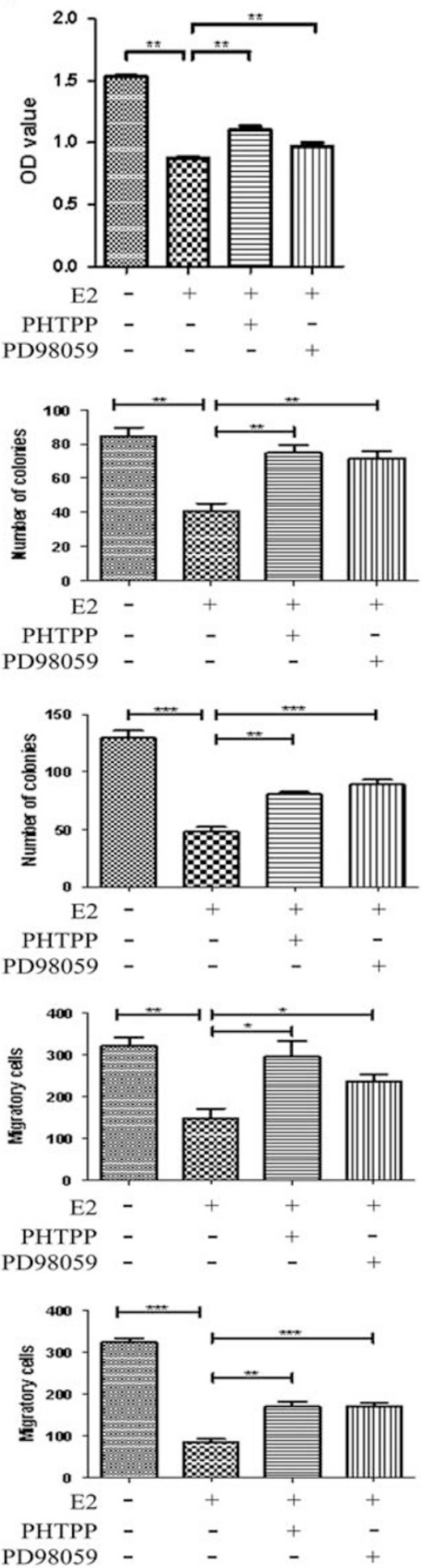

Figure 5 E2-mediated reversion of malignant behaviors of HCC cells through the ER $\beta /$ MAPK/ERK pathway. (a-c) BEL7402 cells (a), SMMC7721 cells (b), and HepG2 cells (c) were pretreated with ER $\beta$ inhibitor PHTPP $(1 \mu \mathrm{M})$ or MAPK pathway inhibitor PD98059 (20 $\mu \mathrm{M})$ for 30 min before E2 (100 nM) treatment for $24 \mathrm{~h}$. Cell viabilities of these HCC cells were detected using CCK-8 kit. (d and e) HepG2 cells (d) and BEL7402 cells (e) were pretreated with PHTPP $(1 \mu \mathrm{M})$ or PD98059 $(20 \mu \mathrm{M})$ for $30 \mathrm{~min}$ before E2 $(100 \mathrm{nM})$ treatment for $24 \mathrm{~h}$. Then, the treated cells were transferred to six-well plates at the density of 1000 cells per well and allowed to grow for 7 days before colony formation assay. Histogram (right panel) represented the corresponding quantitative analysis of the colonies. (f and $\mathbf{g})$ HepG2 cells (f) and BEL7402 cells (g) were pretreated with PHTPP (1 $\mu \mathrm{M})$ or PD98059 (20 $\mu \mathrm{M})$ for 30 min, before treatment with E2 $(100 \mathrm{nM})$ for $24 \mathrm{~h}$. Cell migration assay of the HCC cells were detected by transwell migration assay. Histogram (right pannel) represented the corresponding quantitative analysis of the invaded cells. The presented figures are representative data from at least three independent triplicate experiments. $\left({ }^{*} P<0.05,{ }^{*} P<0.01\right.$, and $\left.{ }^{* *} P<0.001\right)$. HCC, hepatocellular carcinoma. 
these data suggested that reconstitution of NLRP3 inflammasome significantly reversed malignant behaviors of these liver cancer cells.

\section{E2 Reversed Malignant Behaviors of HCC Cells through ER//MAPK/ERK Pathway}

On the basis of the data showing that E2 stimulation induced upregulation of NLRP3 inflammasome components through E2/ER $\beta$-mediated MAPK/ERK pathway, and that reconstitution of NLRP3 inflammasome significantly reversed malignant behaviors of HCC cells, we are then interested to define whether E2 could confer anti-oncogenic effect on HCC cells through ER $\beta /$ MAPK/ERK pathway. To test this, we pretreated the HCC cells with ER $\beta$-specific inhibitor PHTPP or MAPK pathway inhibitor PD98059 before treatment with E2. The cells without inhibitor pretreatment were used as control groups. Our data show that E2 treatment significantly decreased cell viability $(P<0.05$, Figure $5 \mathrm{a}-\mathrm{c})$, colony formation capability (Figure $5 \mathrm{~d}$ and $\mathrm{e}$ ), and migration of HCC cells $(P<0.05$, Figure $5 \mathrm{f}$ and $\mathrm{g}$ ); whereas blockage of E2/ER/MAPK/ ERK pathway by incubation with its specific inhibitors PHTPP and PD98059 effectively reversed the inhibitory effect of E2 on HCC cells $(P<0.05$, Figure $5 \mathrm{a}-\mathrm{g})$. These data further confirmed that E2-mediated reversion of malignant behaviors of HCC cells through ER/MAPK/ERK pathway.

\section{E2 Reversed Malignant Behaviors of HCC Cells by its Upregulation of NLRP3 Inflammasome}

Our data indicate that E2 increased expression of NLRP3 inflammasome components, and inflammasome reconstitution reversed the malignant behaviors of HCC cells; then, we tried to define whether E2 suppressed HCC cells through its upregulation of NLRP3 inflammasome. To verify this, we pretreated the HCC cells with two NLRP3 inflammasome inhibitors, Yvadcmk and Zvadcmk before treatment with E2; and further detected the cell viability, colony formation capability, and invasion capability of the HCC cells. Our data show that reconstitution of NLRP3 inflammasome reversed malignant behaviors of HCC cells in accordance with our previous observation; whereas blockage of NLRP3 inflammasome activation by its inhibitor Yvadcmk and Zvadcmk significantly abolished E2-mediated anti-tumor effect on the HCC cells $\left({ }^{\star} P<0.05, \quad{ }^{*} P<0.01\right.$, and ${ }^{* * *} P<0.001$, Figure 6). These data further demonstrated that E2 inhibited HCC progression through its upregulation of NLRP3 inflammasome.

\section{DISCUSSION}

HCC is one of the most lethal malignancies with notably more prevalence in males worldwide. ${ }^{18-20}$ The reasons for the sex disparity in HCC incidences are not fully understood. In this study, we aimed to clarify the effect of E2/ER $\beta / M A P K$ pathway-mediated NLRP3 inflammasome upregulation in HCC cells and the involvement of its deregulation in HCC progression.

Our data show that expression of estrogen receptor $\beta(\mathrm{ER} \beta)$ was significantly downregulated in liver cancer cells, which correlated with advanced disease status. These data indicate an involvement of ER $\beta$ deregulation in HCC progression. On the basis of our previous data showing the same expression tendency of NLRP3 inflammasome in HCC progression, we are interested to investigate the potential link between ER $\beta$ and NLRP3 inflammasome. In this study, our data surprisingly demonstrated a significant positive correlation between the expression level of ER $\beta$ and NLRP3 inflammasome components. In vitro experiments confirmed the positive regulation of NLRP3 inflammasome by E2 through ER $\beta /$ MAPK pathway.

Our data also show that after treatment with E2, the proliferation, migration, and colony formation capabilities of HCC cells were significantly inhibited in an ER $\beta /$ MAPK pathway-dependent manner, which is consistent with a significantly upregulated expression and activation of NLRP3 inflammasome. We further showed that treatment with inflammasome inhibitors significantly rescued the inhibitory effect of E2 on HCC cells, which verified that the effect of E2 on HCC cells was mediated, at least to a great degree by NLRP3 inflammasome activation.

Given the widespread role of E2 in human physiology, it is not surprising that estrogens are also implicated in the development and progression of many diseases including liver cancer. In contrast with early reports showing cancer promoting role of E2, recent researches showed that E2 conferred protection against cell proliferation and malignant transformation in cancer progression. This protective role of E2 in the gender disparity in hepatocarcinogenesis is recognized in recent years, and several investigations have attempted to address the importance of E2 in the pathogenesis of HCC. ${ }^{3-5,8}$ Naugler et $a l^{5}$ showed that E2 inhibited the release of IL-6 from Kupffer's cells, which further reduced the risk of cancer in female mice in diethylnitrosamine-induced

\footnotetext{
Figure 6 E2 treatment reversed malignant behaviors of HCC cells by its upregulation of NLRP3 inflammasome components. (a and b) HepG2 cells (a) and BEL7402 cells (b) were pretreated with inflammasome inhibitor Yvadcmk $(50 \mu \mathrm{M})$ or Zvadcmk (20 $\mu \mathrm{M})$ for 30 min before treatment with E2 $(100 \mathrm{nM})$ for $24 \mathrm{~h}$. Cell viabilities were detected by CCK-8 analysis. (c and d) HepG2 cells (c) and BEL7402 cells (d) were pretreated with Yvadcmk (50 $\mu$ M) or Zvadcmk $(20 \mu \mathrm{M})$ for 30 min before treatment with E2 $(100 \mathrm{nM})$ for $24 \mathrm{~h}$. The treated cells were transferred to six-well plate for colony formation assay as described previously. Histogram (right panel) represented the corresponding quantitative analysis of the colonies. (e and f) HepG2 cells (e) and BEL7402 cells (f) were treated with inflammasome inhibitor and E2 as described previously. Cell migration assay was performed and histogram (right pannel) represented the corresponding quantitative analysis of the invaded cells. All presented figures are representative data from at least three independent experiments. $\left({ }^{*} P<0.05,{ }^{*} P<0.01\right.$ and $\left.{ }^{* *} P<0.001\right)$. HCC, hepatocellular carcinoma.
} 
hepatic carcinogenesis. Subsequently, Yang et al ${ }^{21}$ showed that E2 suppressed hepatic tumor growth via regulating the polarization of infiltrating macrophages. To our knowledge, this is the first study verifying the role of E2/ER $\beta /$ MAPK signaling-induced NLRP3 inflammasome activation in HCC progression. a

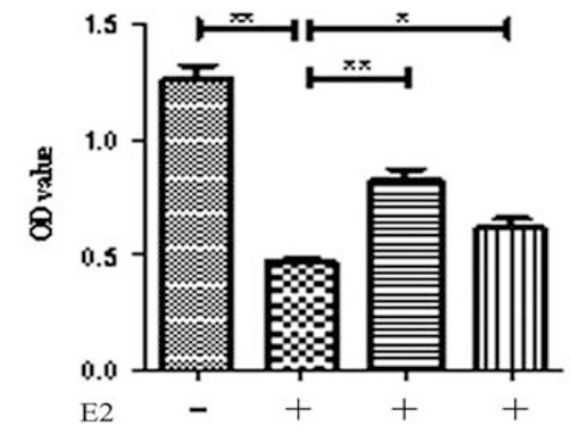

Yvademk - $\quad-\quad+\quad-$ b

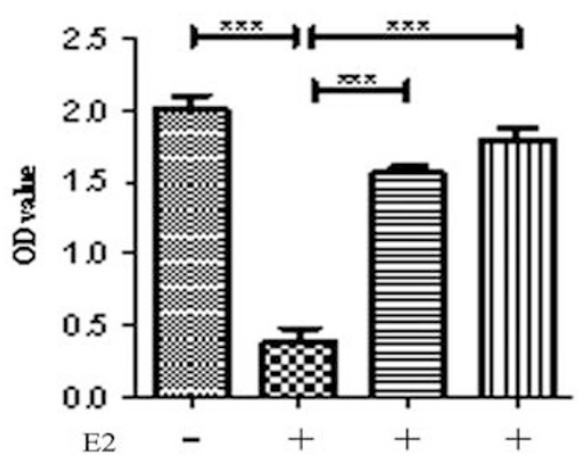

c

Control

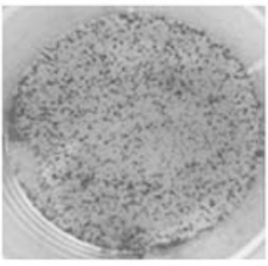

d
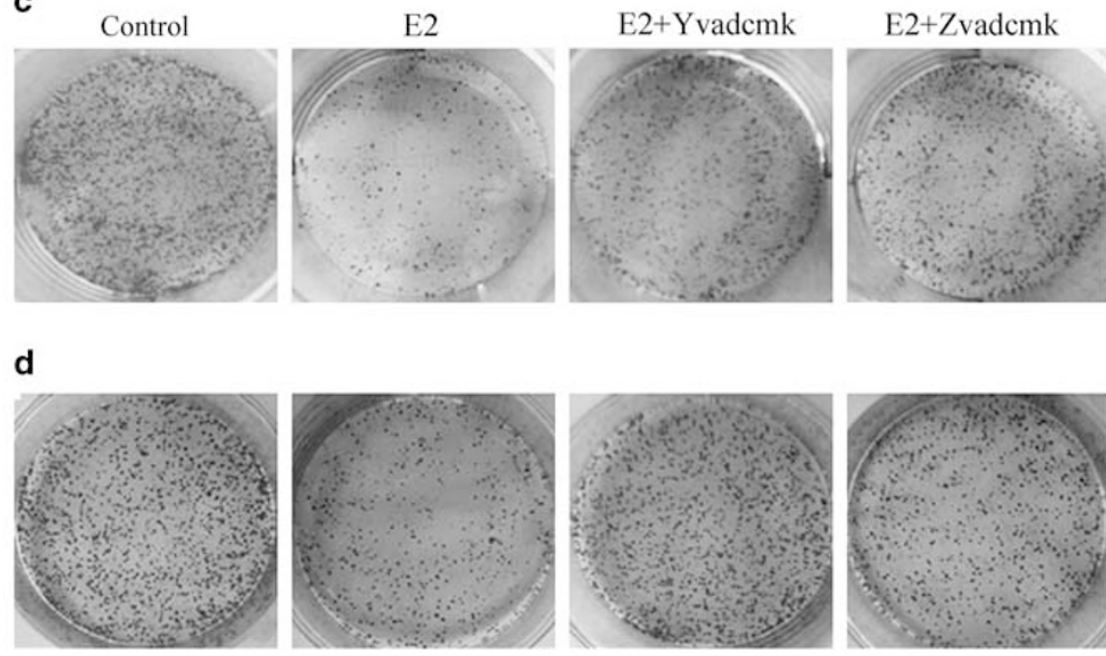

e

Control
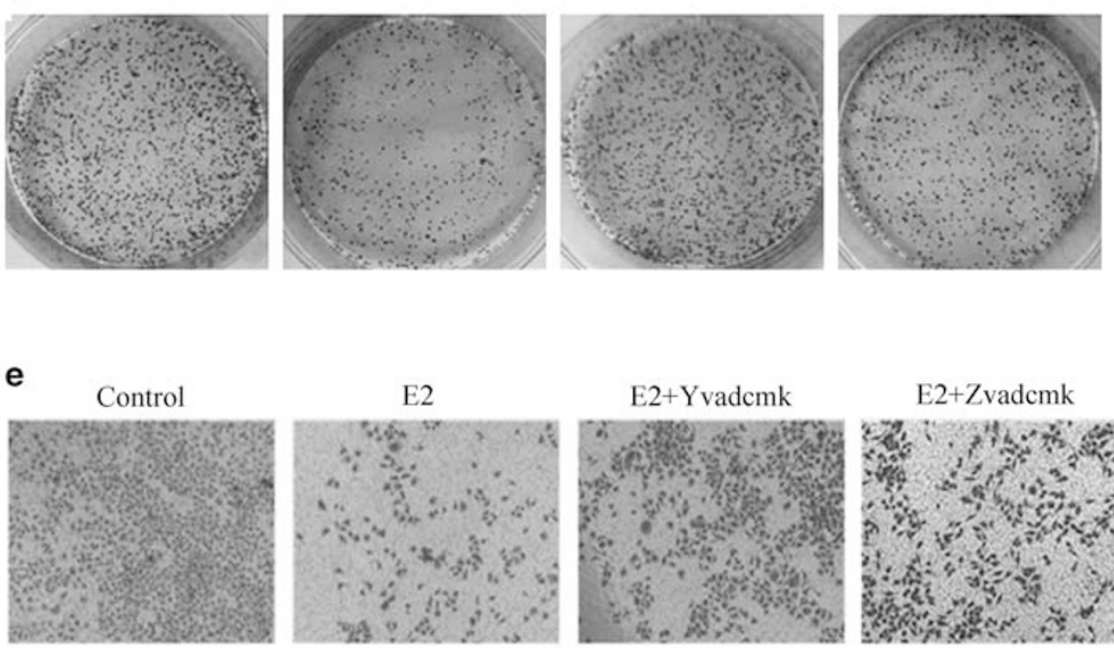

f
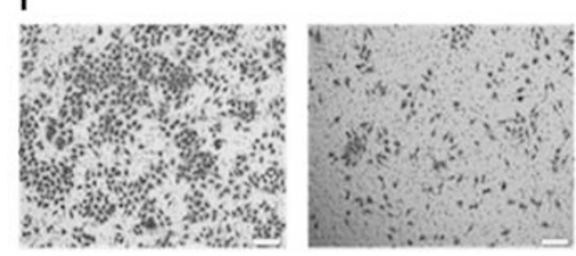

E2+Zvadcmk

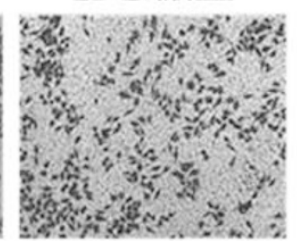

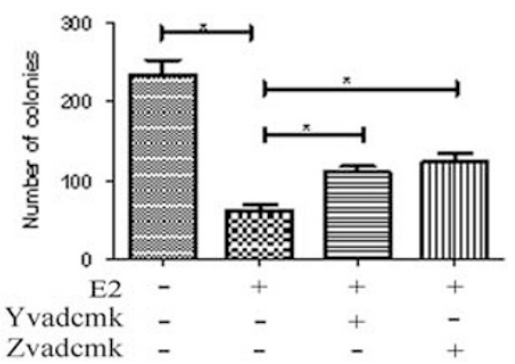
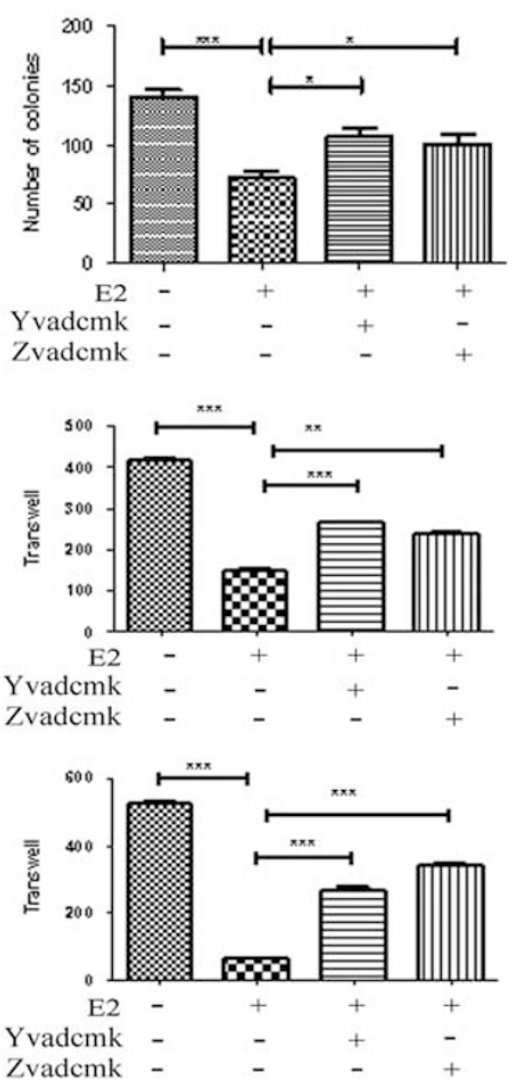

Figure 6 See for caption page on 813. 
The biological activity of E2 is mediated by binding to its specific receptors $\mathrm{ER} \alpha$ and $\mathrm{ER} \beta$. In this study, our investigation showed a protective role of E2 in HCC progression in an E2/ER/MAPK pathway-dependent manner. Although the E2-mediated signaling transduction through MAPK pathway in endometrial carcinoma cells has been reported before, ${ }^{22}$ this E2/ER/MAPK axis was identified for the first time in this study as a regulator of NLRP3 inflammsome in HCC cells. In support of our study showing the tumor suppressor role of $\mathrm{ER} \beta$, there are emerging evidences showing that $\operatorname{ER} \beta$ has an anti-oncogenic role in the development and progression of some tumor types, including ovarian cancer, renal cell carcinoma, prostate cancer, and colon cancers. ${ }^{23-29}$ Our study and these previous reports altogether indicated a protective role of ER $\beta$ in the development and progression of cancer.

Although the role of NLRP3 inflammasome in cancer has been reported, the results are contrasting and conflicting probably due to tissue and organ specificity. Our previous study showed significant downregulation of NLRP3 inflammasome in HCC progression; however, its effect on HCC cells was studied for the first time in this study. Our data reveal that reconstitution of NLRP3 inflammasome significantly reversed the malignant behavior of HCC cells, and the effect of E2 on HCC cells was mediated by NLRP3 inflammasome activation.

NLRP3 inflammsome could induce cleavage and activation of caspase 1, and finally leads to casapse 1-mediated cell death designated pyrotosis. ${ }^{16,17}$ Recent study showed that pyroptotic cell death of hepatocyte mediated liver damage. ${ }^{30}$ Another study showed that NLRP3 inflammasome activation contributed to the progression of non-alcoholic fatty liver disease. ${ }^{31}$ Both of these reports contributed to our understanding of the pathogenesis of liver disease mediated by inflammasome activation. However, the role and regulation of NLRP3 inflammasome activation in liver cancer was first reported in this study. Although both of pyroptosis and apoptosis were reported to be involved in the NLRP3 inflammasome-induced cell death, ${ }^{32,33}$ our data show that only pyroptosis, without apoptosis (data not shown) was involved in the NLRP3 inflammasome activation-induced cell death of HCC cells. This is the first report showing the NLRP3 inflammasome-induced pyroptosis in liver cancer cells.

In conclusion, the present study provides a new sight for the protective role of $\mathrm{E} 2$ in $\mathrm{HCC}$ progression via its regulation of NLRP3 inflammasome through E2/ER/MAPK pathway. Considering the important role of NLRP3 inflammasome in immunological surveillance, manipulating HCC cells through E2/ER $\beta /$ MAPK pathway may be a feasible strategy for treating HCC. Altogether, this study represented a novel molecular mechanism regarding the suppressive effects of estrogen on HCC, adding a new understanding to the gender disparity in HCC progression.

Supplementary Information accompanies the paper on the Laboratory Investigation website (http://www.laboratoryinvestigation.org)

\section{ACKNOWLEDGMENTS}

This study was supported by the National Nature Science Foundation of China (No. 81472269, No. 81172352, and No. 30700357); the Science and Technology Development Project of Shandong Province (No. 2011GGE27020); and Shandong Provincial Doctoral Research Science Foundation (No. BS2013YY037).

\section{DISCLOSURE/CONFLICT OF INTEREST}

The authors declare no conflict of interest.

1. Thomas MB, Jaffe $D$, Choti $M M$ et al. Hepatocellular carcinoma: consensus recommendations of the National Cancer Institute Clinical Trials Planning Meeting. J Clin Oncol 2010;28:3994-4005.

2. El-Serag HB, Mason AC, Key C. Trends in survival of patients with hepatocellular carcinoma between 1977 and 1996 in the United States. Hepatology 2001;33:62-65.

3. Kalra M, Mayes J, Assefa $S$ et al. Role of sex steroid receptors in pathobiology of hepatocellular carcinoma. World J Gastroenterol 2008; 14:5945-5961.

4. Yeh S-H, Chen P-J. Gender disparity of hepatocellular carcinoma: the roles of sex hormones. Oncology 2010;78:172-179.

5. Naugler WE, Sakurai T, Kim S et al. Gender disparity in liver cancer due to sex differences in MyD88-dependent IL-6 production. Science 2007;317:121-124.

6. Kuiper GG, Enmark E, Pelto-Huikko $\mathrm{M}$ et al. Cloning of a novel receptor expressed in rat prostate and ovary. Proc Natl Acad Sci USA 1996;93: 5925-5930.

7. Wei Q, Mu K, Li T et al. Deregulation of the NLRP3 inflammasome in hepatic parenchymal cells during liver cancer progression. Lab Invest 2014;94:52-62.

8. $\mathrm{Xu} \mathrm{H}$, Wei $\mathrm{Y}$, Zhang $\mathrm{Y}$ et al. Oestrogen attenuates tumour progression in hepatocellular carcinoma. J Pathol 2012;228:216-229.

9. Sander LE, Trautwein C, Liedtke C. Is interleukin-6 a gender-specific risk factor for liver cancer? Hepatology 2007;46:1304-1305.

10. Munding C, Keller M, Niklaus $G$ et al. The estrogen-responsive B box protein: a novel enhancer of interleukin-1 beta secretion. Cell Death Differ 2006;13:1938-1949.

11. Cao L, Han L, Zhang Z et al. Involvement of anoikis-resistance in the metastasis of hepatoma cells. Exp Cell Res 2009;315:1148-1156.

12. Zhang Z, Cao L, Li J et al. Acquisition of anoikis resistance reveals a synoikis-like survival style in BEL7402 hepatoma cells. Cancer Lett 2008;267:106-115.

13. Stehlik $C$, Krajewska $M$, Welsh $K$ et al. The PAAD/PYRIN-only protein POP1/ASC2 is a modulator of ASC-mediated nuclear-factor-kappa B and pro-caspase-1 regulation. Biochem J 2003;373:101-113.

14. Stehlik C, Lee SH, Dorfleutner A et al. Apoptosis-associated speck-like protein containing a caspase recruitment domain is a regulator of procaspase-1 activation. J Immunol 2003;171:6154-6163.

15. Broz P, von Moltke J, Jones JW et al. Differential requirement for Caspase-1 autoproteolysis in pathogen-induced cell death and cytokine processing. Cell Host Microbe 2010;8:471-483.

16. Strowig T, Henao-Mejia J, Elinav E et al. Inflammasomes in health and disease. Nature 2012;481:278-286.

17. Wellington $M$, Koselny $K$, Sutterwala FS et al. Candida albicans triggers NLRP3-mediated pyroptosis in macrophages. Eukaryot Cell 2014;13: 329-340.

18. Prieto J. Inflammation, HCC and sex: IL-6 in the centre of the triangle. J Hepatol 2008;48:380-381.

19. Ruggieri A, Barbati C, Malorni W. Cellular and molecular mechanisms involved in hepatocellular carcinoma gender disparity. Int J cancer 2010;127:499-504.

20. Johnson PJ, Krasner N, Portmann B et al. Hepatocellular carcinoma in Great Britain: influence of age, sex, HBsAg status, and aetiology of underlying cirrhosis. Gut 1978;19:1022-1026.

21. Yang W, Lu Y, Xu Y et al. Estrogen represses hepatocellular carcinoma (HCC) growth via inhibiting alternative activation of tumor-associated macrophages (TAMs). J Biol Chem 2012;287:40140-40149.

22. Zhang $L$, Li $X$, Zhao $L$ et al. Nongenomic effect of estrogen on the MAPK signaling pathway and calcium influx in endometrial carcinoma cells. J Cell Biochem 2009;106:553-562.

23. Lazennec G. Estrogen receptor beta, a possible tumor suppressor involved in ovarian carcinogenesis. Cancer Lett 2006;231:151-157. 
24. Bossard $C$, Busson $M$, Vindrieux $D$ et al. Potential role of estrogen receptor beta as a tumor suppressor of epithelial ovarian cancer. PLoS One 2012;7:e44787.

25. Yu CP, Ho JY, Huang YT et al. Estrogen inhibits renal cell carcinoma cell progression through estrogen receptor-beta activation. PLoS One 2013;8:e56667.

26. Lau KM, LaSpina M, Long J et al. Expression of estrogen receptor (ER) alpha and ER-beta in normal and malignant prostatic epithelial cells: regulation by methylation and involvement in growth regulation. Cancer Res 2000;60:3175-3182.

27. Bonkhoff $\mathrm{H}$, Berges $\mathrm{R}$. The evolving role of oestrogens and thei receptors in the development and progression of prostate cancer. Eur Urol 2009;55:533-542.

28. Edvardsson K, Strom A, Jonsson P et al. Estrogen receptor beta induces antiinflammatory and antitumorigenic networks in colon cancer cells. Mol Endocrinol 2011;25:969-979.
29. Edvardsson K, Nguyen-Vu T, Kalasekar SM et al. Estrogen receptor beta expression induces changes in the microRNA pool in human colon cancer cells. Carcinogenesis 2013;34: 1431-1441.

30. Wree A, Eguchi A, McGeough MD et al. NLRP3 inflammasome activation results in hepatocyte pyroptosis, liver inflammation, and fibrosis in mice. Hepatology 2014;59:898-910.

31. Wree A, McGeough MD, Pena CA et al. NLRP3 inflammasome activation is required for fibrosis development in NAFLD. J Mol Med (Berl) 2014;92:1069-1082.

32. Sagulenko V, Thygesen SJ, Sester DP et al. AIM2 and NLRP3 inflammasomes activate both apoptotic and pyroptotic death pathways via ASC. Cell Death Differ 2013;20:1149-1160.

33. Aachoui $Y$, Sagulenko V, Miao EA et al. Inflammasome-mediated pyroptotic and apoptotic cell death, and defense against infection. Curr Opin Microbiol 2013;16:319-326. 